\title{
Connecting the Dots: ethics, global citizenship and tourism.
}

Those of us that recently flocked to popular tourist destinations, such as Barcelona, Venice, Rome, Amsterdam, Florence, Berlin, Lisbon and Palma de Mallorca and beyond, probably encountered a different, grimmer host community than we had envisioned beforehand. Although for many the sun was shining bright(er), the scenery was stunning and the food delicious, there were also signs of a changing attitude, and in some cases visible resistance, towards tourists. Pieces of anti-tourist graffiti that read "Tourists you are the terrorist", "All tourists are bastards" and even "Why call it the tourist season if we can't shoot them?" now (literally) troubled our view at many popular touristic sites. In some cases, for example Barcelona, resentment was even fiercer, resulting in large protests, tyre-slashing and windowsmashing. These actions went beyond merely raising awareness for aggressive and underdressed tourists drinking all day and yelling all night, but were local responses against the economics and morality of all types of mass tourism, which - according to many - impoverishes the poorest in society and everyone's standards of living. While the industry has long upheld its vital contribution to the livelihood of local people, resistance towards tourism development in these touristic hot spots seems to grow every year. Although local governments are trying to cope with this so-called form of 'over-tourism' through scapegoats like tourism restrictions, taxes and other measures, it deflects attention away from the challenges of global tourism development. Restricting the number of tourists or tourism-related activities will do little to solve deep-rooted problems like inequality, exclusion and exploitation. Conversely, we should not forget that at the same time that many protests against yet another season of tourist hordes, in many parts of the world the tourism and hospitality industry are still vital to alleviate distressed economic conditions for many by providing access to critical income and opportunities for prosperity.

As tourism is highly connected to everyday practices and places, and increasingly contested for its impacts, 'ethics are, or should be, integral to all aspects of it' (Burns, 2015: 117). Ethical issues, despite attracting growing attention within both academic and public debates, often remain side-lined or regarded as a 'thing' that can be added to increase economic growth and prosperity (Smith and Duffy, 2003; Lovelock and Lovelock, 2013; Fennell, 2006). To a certain degree this accepted neglect is understandable from a practical point of view, not only because ethics presents an array of options for ascribing value, they are often also abstract and vary according to the situation and culture in which they are applied. In today's context, however, there's an increasing understanding that we are facing challenges that transcend all socio-spatial categories into which we have organised ourselves. As such, Smith (2009: 629) argues, tourism cannot be free of ethics as they make us mindful of the importance of resisting a worldview which would reduce everything to economic object, commodities to be bought and sold'. Instead, ethics in tourism is about our moral commitments as humans about being human (Lovelock and Lovelock, 2013) and responding to the suffering of others. In this state of affairs, the notion of global citizenship seems ever more important as we increasingly discuss and question the (presumed) rights, freedoms and responsibilities within and beyond the context of tourism (Bianchi, 2013). Tourism, in this regards, is no less than a worldmaking force (Hollinshead, 2008); on the one hand bringing people together by offering spaces for encounters, and in doing so potentially fostering understanding and peace whilst, on the other hand, in reality encounters between hosts and guests can go terribly wrong as, too often, locals feel disrespected by those who visit their spaces and disregarded by policy 
makers and destination managers who often show little concerns for the local culture or the environment. Instead, we must aim to establish a 'democracy without frontiers' by recognising the worth of all people - residents, tourists and workers in the industry - as well as their right to self-determination. When we accept that a global industry requires global ethics and a common effort to work together across borders (instead of between barriers) we will be able to lay the foundations for a truly sustainable approach to tourism.

It was this belief that inspired the International conference 'Connecting the Dots', held at Saxion University of Applied Sciences in July 2017, and, subsequently, the need for a Special Issue that merged ethics and global citizenship in a tourism context. Inspired by an array of critical conference presentations and sharp discussants, and with great support from Jennie Germann-Moltz, a co-editor of Hospitality \& Society, we soon drafted the outline and purpose for this Special Issue, which is to gather insights that address, explore, merge and critique the connections between ethics, global citizenship and tourism as goals in and of themselves. The collective task of the contributors was to examine and debate these intersections through conceptual, theoretical, methodological and empirical insights to advance knowledge and understanding, and which critically seek also to inform our actions in tourism research, policy making and daily practices. We welcomed papers that engaged with global citizenship and ethical approaches to tourism, shifting away from considerations of what ethics and global citizenship are but how they can be used to inform behaviour in a tourism context (and vice versa).

The papers eventually included in this Special Issue address many of the moral dilemmas involved in the development, operation, management and consumption of tourism and hospitality. In doing so, they also touch upon a range of topics and approaches in different contexts, further demonstrating the malleability, openness and conceptual richness of emerging insights on the intersections between ethics and global citizenship in tourism and hospitality studies. Although it was impossible, nor our intention, with this Special Issue to cover all types of ethical dilemmas and forms of citizenship in every kind of tourism, we focussed on those papers that elucidate some of the most significant present-day issues.

This first of these, from Hannah Baker and Dianne Dredge, explores the meaning of global citizenship for employees working at a Danish travel-related NGO in Denmark. Exploring the specific influence of Denmark's political and cultural values on the populations' attitudes towards global citizenship, the authors were interested to understand how this unique lens informed participants' view of themselves as global citizens. Using a narrative approach, participants were asked to reflect on previous travel experiences and consider how these influenced and gave meaning to their moral commitments in life. The authors conclude by reminding us of the heterogeneous meaning of global citizenship, warning against the perpetuation of paternalistic and privileged framings of moral responsibility, and advising educators of the importance of creating curricula that foster self awareness, critical reflection and political understanding to enable students to appreciate and promote a just, caring and responsible society.

The second paper, by Judith Romhild-Raviart et al. explores whether tourists critically reflect on the (un)sustainability of their cruise holidays in personal blogs. Critical insight into tourists' attitudes towards the impacts of their travel across all three pillars of sustainability - social, 
economic, environmental - is relatively scarce, and not yet addressed in the cruise literature. To fill this gap, a selection of cruise-related posts from a global travel blog portal were examined using a range of keywords related to sustainability. Thematic analysis revealed some reflection although this was largely superficial and often self-oriented. The authors call for more researchers to critically engage cruise passengers across all social media platforms in prompted discussions about the sustainability of their cruise holidays. Areas of particular concern across the tourism and hospitality industry, and not often included in discussion of sustainability in tourism, are social dimension issues such as staff working conditions, tipping policies, emotional labour and 'Othering' of employees and/or destination residents. The authors conclude by arguing it is only by achieving such dialogue and educating passengers on sustainability that the cruise industry may be encouraged to work collaboratively, cooperatively and transparently with them and other key stakeholders towards a more sustainable industry.

The third paper, by Lourdes Zamanillo and Joseph Cheer, examines the conditions that govern and shape empathy between hosts and guests during a 10-day pro-social cycling tour in Cambodia. In doing so, they aim to explore whether pro-social tourism has potential to harness empathy, and to identify key elements that either enable or constrain the development of empathy amongst the tour's participants. Building on research that explores the roles, manifestations and risks of empathy across areas such as hospitality, tourism and voluntourism, the findings suggest that obstacles such as language barriers and unequal power relationships limit the development of empathy between hosts and guests through pro-social tourism. Consequently, they argue that empathy in host-guest relationships emerges when there are opportunities to participate in bilateral conversations in settings where power differences are reduced. Future research is needed to explore these relationships to create deeper understandings about whether the role of empathy in crosscultural understandings and its potential to change behaviours and attitudes that support more equitable ways of living and thinking in the long-term.

The fourth and final paper in this special issue, by Solene Prince, draws attention to the dominant volunteer-centric discourse in research into the benefits of volunteer tourism. Taking the case study of Solheimar, an eco-village community in Iceland, Prince extensively critiques the concepts of transformative learning and global citizenship education, noting how community members' physical and emotional needs are often swept aside in favour of proving a meaningful learning experience for international volunteers. Taking an ethnographic approach with on-site observations and interviews, the author reveals the complex dynamics and conflicting goals among and between Solheimars' volunteers, community members and education coordinators. She concludes with a call for researchers to focus less on volunteer experiences and more on inclusive critical reflection with a greater emphasis on hearing the voices of host communities.

In conclusion, the discussions reveal a number of ethical responsibilities that fundamentally influence how people interact and connect with each other across all aspects of travel, and which have a critical role to play before, during and after tourist and host encounters and experiences. Specifically, these involve inequitable power relations in policy decision-making, the challenges of inclusion, access and mobilities in an industry often associated with exploitation and exclusion, and scenarios where colonialist perspectives rather than global 
citizenship pervade general attitudes and communication. Nevertheless, while these papers make significant contribution to knowledge of the intersections between tourism, ethics and global citizenship, there remain opportunities for further debate in these and related areas, which will undoubtedly continue beyond this Special Issue. It is our view that researchers, academics and critical commentators share a collective moral responsibility to continually interrogate all aspects of the tourism and hospitality industry to ensure its foundations are rooted in a just, humanitarian and globally ethical framework.

References

(Bianchi, 2013).

Burns, G.L. (2015)

The Routledge handbook of tourism and sustainability

117-26

Smith and Duffy, 2003;

Lovelock and Lovelock, 2013;

Fennell, 2006

Smith (2009: 629) 